\title{
Excessive daytime sleepiness in secondary chronic headache from the general population
}

\author{
Espen Saxhaug Kristoffersen ${ }^{1,2^{*}} \mathbb{D}$, Knut Stavem ${ }^{3,4,5}$, Christofer Lundqvist ${ }^{3,5,6}$ and Michael Bjørn Russell ${ }^{1,3}$
}

\begin{abstract}
Background: Excessive daytime sleepiness (EDS, defined as Epworth sleepiness scale score $>10$ ) is a common symptom, with a prevalence of $10-20 \%$ in the general population. It is associated with headache and other chronic pain disorders. However, little is known about the prevalence of EDS among people with secondary chronic headaches.

Findings: A total of 30,000 persons aged 30-44 from the general population was screened for headache by a questionnaire. The 633 eligible participants with self-reported chronic headache were interviewed and examined by a headache specialist who applied the International Classification of Headache Disorders with supplementary definitions for chronic rhinosinusitis and cervicogenic headache. A total of 93 participants had secondary chronic headache and completed the ESS.

A total of 47 participants had chronic post-traumatic headache (CPTH) and/or cervicogenic headache (CEH), 39 participants had headache attributed to chronic rhinosinusitis (HACRS), while 7 had other secondary headaches. 23. $3 \%$ of those with CPTH, CEH or HACRS reported EDS. In multivariable logistic regression analysis the odds ratios of EDS were not significantly different in people with CPTH/CEH or HACRS.
\end{abstract}

Conclusion: Almost one out of four subjects with secondary chronic headache reported EDS with no differences between the various secondary chronic headaches.

Keywords: Epworth sleepiness scale, Sleep, Posttraumatic headache, Rhinosinusitis, Cervicogenic, Migraine, Population-based

\section{Introduction}

Headache and sleep complaints are prevalent in the general population and often coexist in the same subject [1]. Excessive daytime sleepiness (EDS) is associated with neurological disorders and pain [2,3]. Only a few studies have investigated EDS in headache [4-10], and the results are not uniform, possibly due to differences in methods and patient populations [4-10]. We have previously reported on the prevalence of EDS in primary chronic headaches in the general population [11].

\footnotetext{
* Correspondence: e.s.kristoffersen@medisin.uio.no

${ }^{1}$ Head and Neck Research Group, Research Centre, Akershus University

Hospital, PO Box 95, 1478 Lørenskog, Norway

${ }^{2}$ Department of General Practice, Institute of Health and Society, University of

Oslo, Oslo, Norway

Full list of author information is available at the end of the article
}

To our knowledge EDS has not been evaluated in people with secondary chronic headache. Thus, in the present study we investigated the prevalence of, and factors associated with EDS in participants from the general population with different secondary chronic headaches.

\section{Findings \\ Methods}

\section{Study design, population and variables}

This was a cross-sectional epidemiological survey of 30,000 representative persons aged 30-44 drawn from the general population of eastern Akershus County, Norway. A postal questionnaire screened for possible chronic headache $(\geq 15$ days/last month and/or $\geq 180$ days/last year). Screening-positive subjects were invited to a clinical interview at Akershus University Hospital. 
In total $71 \%(20,598 / 28,871)$ of the study population responded to the screening questionnaire. Of 935 patients with self-reported chronic headache, 633 participated in clinical interviews (490 as an ambulatory visit, 143 by telephone). The method has been described in detail elsewhere [12, 13].

After the interview, the participants filled in a selfadministered questionnaire including the Epworth Sleepiness Scale (ESS) [14]. The participants also provided information on socio-demographics, height, weight, smoking status, medication-overuse, headache frequency and headache disability by Migraine Disability Assessment (MIDAS) [15].

\section{Headache classification}

The International Classification of Headache Disorders (ICHD-II) was applied in the interview. The diagnoses were later reclassified according to ICHD III $\beta$ [16]. Those with secondary chronic headache exclusively due to medication overuse were excluded.

Chronic headache was defined as headache $\geq 15$ days/ months for at least 3 months or $\geq 180$ days/year. Chronic post-traumatic headache $(\mathrm{CPTH})$ included head and whiplash traumas. Cervicogenic headache $(\mathrm{CEH})$ was classified according to the criteria of the Cervicogenic Headache International Study Group, requiring at least three criteria to be fulfilled, not including blockade of the neck due to the non-interventional nature of our study (Table 1) [17]. Headache attributed to chronic rhinosinusitis (HACRS) was defined according to the criteria established by the American Academy of Otolaryngology - Head and Neck Surgery (Table 2) adding that the symptoms had persisted for 12 weeks or more [18].

\section{Excessive daytime sleepiness}

The ESS questionnaire describes eight daily situations in which the respondents estimate their likelihood of dozing off on a $0-3$ scale, i.e. $0=$ no chance, $1=$ slight chance, 2 = moderate chance, $3=$ high chance [14]. The ESS total scores $(0-24)$ were dichotomized into scores $\leq 10$ and $>10$; the latter is considered to be clinically significant EDS [19].

\section{Statistical analysis}

For descriptive data, proportions, means and SDs or 95\% confidence intervals (CI) are given. We estimated binomial confidence intervals for proportions. Groups were compared using the $t$-test (continuous data) or the $X^{2}$ test (categorical data).

Logistic regression models were used to evaluate presence of EDS as the dependent variable in secondary chronic headaches. Because of the low prevalence of EDS in the sample, we restricted the number of
Table 1 Definition of cervicogenic headache [17]

\begin{tabular}{|c|c|}
\hline Major criteria & $\begin{array}{l}\text { I. Symptoms and signs of neck involvement } \\
\text { la. Precipitation of head pain, similar to the } \\
\text { usually occurring one: la1) by neck movement } \\
\text { and/or sustained, awkward head positioning, } \\
\text { and/or: la2) by external pressure over the } \\
\text { upper cervical or occipital region on the } \\
\text { symptomatic side. } \\
\text { Ib. Restriction of the range of motion (ROM) in } \\
\text { the neck. } \\
\text { Ic. Ipsilateral neck, shoulder or arm pain of a } \\
\text { rather vague, non-radicular nature, or - } \\
\text { occasionally - arm pain of a radicular nature. } \\
\text { II. Confirmatory evidence by diagnostic } \\
\text { anaesthetic blockades. } \\
\text { III. Unilaterality of the head pain, without } \\
\text { sideshift. }\end{array}$ \\
\hline $\begin{array}{l}\text { Head pain } \\
\text { characteristics }\end{array}$ & $\begin{array}{l}\text { IV. Moderate-severe, non-throbbing pain, usually } \\
\text { starting in the neck. Episodes of varying } \\
\text { duration, or: fluctuating, continuous pain. }\end{array}$ \\
\hline $\begin{array}{l}\text { Other characteristics of } \\
\text { some importance }\end{array}$ & $\begin{array}{l}\text { V. Only marginal effect or lack of effect of } \\
\text { indomethacin. Only marginal effect or lack of } \\
\text { effect of ergotamine and sumatriptan. } \\
\text { Female sex. Not infrequent occurrence of } \\
\text { head or indirect neck trauma by history, } \\
\text { usually of more than only medium severity. }\end{array}$ \\
\hline $\begin{array}{l}\text { Other features of lesser } \\
\text { importance }\end{array}$ & $\begin{array}{l}\text { VI. Various attack-related phenomena, only } \\
\text { occasionally present, and/or moderately } \\
\text { expressed when present: a) nausea, b) } \\
\text { phono- and photophobia, c) dizziness, d) } \\
\text { ipsilateral "blurred vision", e) difficulties } \\
\text { swallowing, f) ipsilateral oedema, mostly in } \\
\text { the periocular area. }\end{array}$ \\
\hline
\end{tabular}

It is obligatory that one or more of the phenomena la-lc are present

Table 2 Definition of rhinosinusitis by the American Academy of Otolaryngology Head and Neck Surgery [18]

Major factors
Facial pain/pressure
Nasal obstruction/blockage
Nasal discharge/purulence/discolored postnasal drainage
Hyposmia/anosmia
Purulence in nasal cavity on examination
Fever (acute rhinosinusitis)
Minor factors
Headache
Fever (all nonacute)
Halitosis
Fatigue
Dental pain
Cough
Ear pain/pressure/fullness

Two major factors or one major and two minor factors are required for the diagnosis. Of note, facial pain requires another major factor associated with it for diagnosis, as facial pain plus two minor factors is not deemed sufficient for diagnoses of rhinosinusitis 
independent variables in multivariable analysis to three. All logistic regression models were estimated using penalized likelihood to reduce small-sample bias in maximum likelihood estimation [20, 21]. We conducted (1) bivariate analysis with type of chronic headache, i.e. CPTH/CER or HACRS, medication overuse (yes or no), and a propensity score (the propensity for having HACRS compared to CPTH/CER in a multivariable logistic regression model with age, sex, headache frequency, and concomitant migraine as independent variables), and (2) multivariable analysis forcing all three independent variables into the model. The results are presented with odds ratios (ORs) with 95\% CIs.

Significance levels were set at $p<0.05$, using twosided test. All statistical analyses were performed using Stata version 14.2 (StataCorp, College Station, TX).

\section{Ethical issues}

The Regional Committee for Medical Research Ethics and the Norwegian Social Science Data Services approved the study. All participants gave informed consent.

\section{Results}

In total 93 of the 113 eligible participants (82\%) completed the ESS. Respondents and non-respondents to the ESS did not differ in age, gender composition or the distribution of headache diagnoses (data not shown).

A total of 36 people had $\mathrm{CPTH}, 19$ people had $\mathrm{CEH}$ and 40 people had HACRS. Co-occurrence of CPTH and CEH was found in 7 people, while one person had cooccurrence of CPTH and HACRS. Six persons had other secondary chronic headaches, i.e. 3 post-craniotomy, 1 diving related, 1 pregnancy-related, and 1 post-meningitis.

Table 3 Descriptive statistics for respondents with chronic posttraumatic headache/cervicogenic headache vs. headache attributed to chronic rhinosinusitis. Number (\%) unless stated otherwise

\begin{tabular}{|c|c|c|c|}
\hline & Posttraumatic/cervicogenic headache $(N=47)$ & Rhinosinusitis headache $(N=39)$ & $p$-value \\
\hline Age, mean (SD) & $38.9(4.2)$ & $38.9(3.8)$ & 0.97 \\
\hline Gender & & & 0.09 \\
\hline Female & $34(72)$ & $34(87)$ & \\
\hline Male & $13(28)$ & $5(13)$ & \\
\hline Education, highest attained & & & 0.37 \\
\hline$<11$ years & $9(19)$ & $6(15)$ & \\
\hline $11-15$ years & $27(57)$ & $25(64)$ & \\
\hline$>15$ years & $11(24)$ & $8(21)$ & \\
\hline Body mass index $\left(\mathrm{kg} / \mathrm{m}^{2}\right)$, mean (SD) & $27.6(5.3)^{\mathrm{a}}$ & $25.5(4.5)^{\mathrm{b}}$ & 0.08 \\
\hline Daily smoker & & & 0.61 \\
\hline No & $16(36)$ & $16(41)$ & \\
\hline Yes & $29(64)$ & $23(59)$ & \\
\hline Concomitant migraine & & & 0.23 \\
\hline No & $29(62)$ & $19(49)$ & \\
\hline Yes & $18(38)$ & $20(51)$ & \\
\hline Medication-overuse & & & 0.65 \\
\hline No & $24(51)$ & $18(46)$ & \\
\hline Yes & $23(49)$ & $21(54)$ & \\
\hline Number of headache days past 3 months & & & 0.001 \\
\hline$<90(\mathrm{Q} 1-\mathrm{Q} 3)$ & $24(53)$ & $32(89)$ & \\
\hline$\geq 90(\mathrm{Q} 4)$ & $21(47)$ & $4(11)$ & \\
\hline MIDAS score (grade) & & & 0.038 \\
\hline 0-20 (Little/no to moderate disability) & $9(22)$ & $15(45)$ & \\
\hline > 20 (Severe disability) & $31(78)$ & $18(55)$ & \\
\hline Epworth sleepiness scale score, mean (SD) & $6.8(4.5)$ & $7.3(4.2)$ & 0.60 \\
\hline Excessive daytime sleepiness (ESS score $>10$ ) & & & 0.63 \\
\hline No & $37(79)$ & $29(74)$ & \\
\hline Yes & $10(21)$ & $10(26)$ & \\
\hline
\end{tabular}

${ }^{a} n=36,{ }^{b} n=35$ 
Table 4 Prevalence (\%) of excessive daytime sleepiness (ESS >10) in people with secondary chronic headache

\begin{tabular}{|c|c|c|c|c|c|c|}
\hline & \multicolumn{2}{|c|}{ Posttraumatic/ cervicogenic headache } & \multicolumn{2}{|c|}{ Rhinosinusitis headache } & \multicolumn{2}{|c|}{ Total } \\
\hline & $\mathrm{N}$ & Prevalence (95\% Cl) & $\mathrm{N}$ & Prevalence $(95 \% \mathrm{Cl})$ & $\mathrm{N}$ & Prevalence $(95 \% \mathrm{Cl})$ \\
\hline Men & 13 & $30.8(12.7$ to 57.6$)$ & 5 & 20.0 (3.6 to 62.4$)$ & 18 & $27.8(12.5$ to 50.9$)$ \\
\hline Women & 34 & 17.6 (8.3 to 33.5$)$ & 34 & 26.5 (14.6 to 43.1$)$ & 68 & 22.1 (13.8 to 33.3) \\
\hline All & 47 & $21.3(12.0$ to 34.9$)$ & 39 & 25.6 (14.6 to 41.1$)$ & 86 & 23.3 (15.6 to 33.2$)$ \\
\hline
\end{tabular}

Seven of those with $\mathrm{CPTH}$, seven of those with $\mathrm{CEH}$ and ten of those with HACRS reported EDS, respectively. Only one of those with other secondary chronic headache reported EDS.

The people with $\mathrm{CPTH}$ and $\mathrm{CEH}$ were descriptive similar (gender, co-occurrence of migraine, medication overuse, ESS or EDS) and were merged for the purpose of statistical analyses. We included people with CPTH/ CER and HACRS in the main analyses and excluded those seven persons with other secondary chronic headaches due to the low numbers and consequent statistical limitations.

The respondents with CPTH/CER had a higher proportion of subjects with headache frequency above the 75th percentile ( $\geq 90$ headache days the past 3 months) and more severe disability than those with HACRS (Table 3).

The overall prevalence of EDS was 23\% (95\% CI 16-33) among those with CPTH, CER or HACRS; $22 \%$ (95\% CI 14-33) among women and 28\% (95\% CI 13-51) among men (Table 4). The prevalence of EDS in $\mathrm{CPTH} / \mathrm{CER}$ without versus with co-occurrence of migraine was $24 \%$ (95\% CI 12-42) and $17 \%$ (95\% CI $6-39)$, respectively $(p=0.54)$. The prevalence of EDS in HACRs without versus with co-occurring migraine was $16 \%$ (95\% CI 6-38) and 35\% (95\% CI 18-57), respectively $(p=0.17)$.

Headache diagnosis, medication overuse or the composite propensity score (age, gender, headache frequency and co-occurring migraine) was not associated with EDS in bivariate or multivariable analysis (Table 5).

Applying the $\chi^{2}$-test in non-adjusted analyses, no significant differences (data not shown) were found in those with and without EDS depending on socio- demographics, body mass index, smoking, alcohol, caffeine, other sleep disorders, anxiety/depression, comorbidity of other disorders or medication use for other conditions.

\section{Discussion}

In this large population-based study almost one out of four subjects with secondary chronic headache reported EDS. The main finding was that the prevalence of EDS did not differ between those with $\mathrm{CPTH} / \mathrm{CEH}$ and HACRS. Furthermore, medication-overuse, or the composite propensity score (age, gender, headache frequency and co-occurring migraine) was not associated with EDS in this population.

No previous study has investigated EDS for secondary chronic headache in the general population. The prevalence of EDS in men and women with secondary chronic headache corresponds to that for people with primary chronic headache in the general population $(20.6 \%$ among women, $22.5 \%$ among men) and is comparable to data reported from the Norwegian general population (16.1\% among women, $20.1 \%$ among men) [11, 22]. Here, we did not include a directly comparable headache-free control group and caution is therefore warranted in this comparison. Also, due to the limited sample size in the present study, the risk of type 2 errors must be considered.

Little is known about the precise relationship between headache and sleep problems, when these occur concurrently. An association between EDS and different pain conditions has been reported [2,3]. Pain may disturb sleep and give rise to EDS, but sleep loss and EDS may also contribute to pain. Some of these secondary

Table 5 Odds for having EDS, defined as ESS > 10. Penalized maximum likelihood logistic regression

\begin{tabular}{|c|c|c|c|c|c|c|c|c|}
\hline \multirow[b]{2}{*}{ Covariate } & \multirow[b]{2}{*}{$n$} & \multicolumn{2}{|c|}{ Bivariate $(n=81-86)$} & \multirow[b]{2}{*}{$P$} & \multirow[b]{2}{*}{$n$} & \multicolumn{2}{|c|}{ Multivariable $(n=81)$} & \multirow[b]{2}{*}{$P$} \\
\hline & & Odds ratio & $95 \% \mathrm{Cl}$ & & & Odds ratio & $95 \% \mathrm{Cl}$ & \\
\hline \multicolumn{9}{|l|}{ Headache type } \\
\hline Posttraumatic/cervicogenic ${ }^{a}$ & 47 & 1 & & & 45 & 1 & & \\
\hline Rhinosinusitis & 39 & 1.27 & (0.48 to 3.39$)$ & 0.63 & 36 & 1.71 & (0.55 to 5.35$)$ & 0.35 \\
\hline \multicolumn{9}{|l|}{ Medication-overuse } \\
\hline $\mathrm{No}^{\mathrm{a}}$ & 42 & 1 & & & 41 & 1 & & \\
\hline Yes & 44 & 0.44 & (0.16 to 1.21$)$ & 0.11 & 40 & 0.44 & (0.16 to 1.25$)$ & 0.12 \\
\hline Propensity score (age, sex, headache frequency, migraine) & 81 & 0.77 & (0.07 to 8.33$)$ & 0.83 & 81 & 0.35 & (0.02 to 5.53$)$ & 0.45 \\
\hline
\end{tabular}

${ }^{\mathrm{a}}$ Reference category 
headaches are poorly understood, thus, further research is warranted [23]. Studies suggest that CEH can be explained by local factors in the neck with dysfunction of the neck muscles and mechanical cervical spine pathology leading to limited cervical movements and projection of the pain [24]. Headaches attributed to head trauma and whiplash trauma have instead been suggested to represent an interplay between the physical injury, neuroinflammation, psychological disturbances and emotional stress of the accident [25, 26]. Finally, longstanding oedema of the nasal mucosa and rhinosinal inflammation result in chronic rhinosinusitis which may give chronic headache [12]. The present study reported that $\mathrm{CPTH} / \mathrm{CEH}$ and HACRS had similar prevalence of EDS despite these different headache forms probably being caused by different pathophysiological mechanisms. Therefore, it may be the complex burden of pain, more than the specific condition that is associated with EDS. Furthermore, the prevalence was comparable to that of two other different headache entities; chronic migraine and chronic tension-type headache [11].

The population-based sample in the present study was large, and the high response rate should ensure that the sample was representative of the general population. Even though the sample size of secondary chronic headache may seem small, this is the largest sample of subjects with secondary chronic headache recruited from the general population.

The diagnostic criteria of CEH and HACRS have been discussed for many years $[12,27]$. When the study was conducted the more vague ICHD-II criteria for $\mathrm{CEH}$ were in use and HACRS was not recognized as a cause of chronic headache. Thus, to improve the diagnostic accuracy we used supplementary definitions. All patients diagnosed with CEH or HACRS in the present study fulfil the new ICHD-III $\beta$ criteria for these chronic headaches.

Face-to-face interviews by headache experts, as in the present study, provide more valid headache diagnoses than questionnaire-based studies [28]. The ESS is a widely used, validated questionnaire for evaluating subjective daytime sleepiness, and the score is associated with clinically important outcomes, such as cognitive impairment, cardiovascular mortality, and injuries [29, 30].

The 30-44 years age range in our study was chosen in order to ascertain a general population sample without much co-morbidity of non-headache disorders. Because EDS varies with age, our findings may not be generalizable to younger or older populations. The study lacked data on sleep quality and sleep duration that may be associated with sleepiness in headache $[5,6,8,9]$.

The overall sample size limited the number of variables that could be analyzed as potential confounders, and this also lead us to dichotomize many variables for use in the analyses. Also, due to the small number in the present study, the risk of type 2 errors must be considered. Finally, the cross-sectional design in the present study does not permit any conclusions about causality.

In conclusion, there was no difference in the prevalence of EDS between subgroups of different secondary chronic headache diagnoses.

\section{Acknowledgments}

Kjersti Aaseth and Ragnhild Berling Grande conducted the clinical interviews.

\section{Funding}

This study was supported by grants from the South East Norway Regional Health Authority and Institute of Clinical Medicine, Campus Akershus University Hospital, University of Oslo.

\section{Authors' contributions}

MBR had the original idea for the study and planned the overall design together with CL. All authors were involved in the planning and interpretation of the data analysis. ESK and KS conducted the data analysis. ESK prepared the initial draft. All authors have commented on, revised and approved the final manuscript.

\section{Competing interest}

All authors declare that they have no competing interest.

\section{Publisher's Note}

Springer Nature remains neutral with regard to jurisdictional claims in published maps and institutional affiliations.

\section{Author details}

${ }^{1}$ Head and Neck Research Group, Research Centre, Akershus University Hospital, PO Box 95, 1478 Lørenskog, Norway. ${ }^{2}$ Department of General Practice, Institute of Health and Society, University of Oslo, Oslo, Norway. ${ }^{3}$ Institute of Clinical Medicine, Campus Akershus University Hospital, University of Oslo, Oslo, Nordbyhagen, Norway. ${ }^{4}$ Department of Pulmonary Medicine, Medical Division, Akershus University Hospital, Lørenskog, Norway. ${ }^{5} \mathrm{H} \varnothing \mathrm{KH}$, Research Centre, Akershus University Hospital, Lørenskog, Norway.

${ }^{6}$ Department of Neurology, Akershus University Hospital, Lørenskog, Norway.

Received: 20 June 2017 Accepted: 4 August 2017

Published online: 16 August 2017

References

1. Rains JC, Poceta JS, Penzien DB (2008) Sleep and headaches. Curr Neurol Neurosci Rep 8:167-175

2. Wolfe F, Michaud K, Li T (2006) Sleep disturbance in patients with rheumatoid arthritis: evaluation by medical outcomes study and visual analog sleep scales. J Rheumatol 33:1942-1951

3. Dyken ME, Afifi AK, Lin-Dyken DC (2012) Sleep-related problems in neurologic diseases. Chest 141:528-544

4. Peres MF, Stiles MA, Siow HC, Silberstein SD (2005) Excessive daytime sleepiness in migraine patients. J Neurol Neurosurg Psychiatry 76:1467-1468

5. Barbanti P, Aurilia C, Egeo G, Fofi L, Vanacore N (2013) A case-control study on excessive daytime sleepiness in chronic migraine. Sleep Med 14:278-281

6. Seidel S, Hartl T, Weber M, Matterey S, Paul A, Riederer F et al (2009) Quality of sleep, fatigue and daytime sleepiness in migraine - a controlled study. Cephalalgia 29:662-669

7. Odegard SS, Engstrom M, Sand T, Stovner LJ, Zwart JA, Hagen K (2010) Associations between sleep disturbance and primary headaches: the third Nord-Trondelag Health Study. J Headache Pain 11:197-206

8. Stavem K, Kristiansen HA, Kristoffersen ES, Kvaerner KJ, Russell MB (2017) Association of excessive daytime sleepiness with migraine and headache frequency in the general population. J Headache Pain 18:35

9. Kim J, Cho SJ, Kim WJ, Yang Kl, Yun CH, Chu MK (2016) Excessive daytime sleepiness is associated with an exacerbation of migraine: A populationbased study. J Headache Pain 17:62

10. Karthik N, Kulkarni GB, Taly AB, Rao S, Sinha S (2012) Sleep disturbances in 'migraine without aura'-a questionnaire based study. J Neurol Sci 321:73-76 
11. Kristoffersen ES, Stavem K, Lundqvist C, Russell MB (2017) Excessive daytime sleepiness in chronic migraine and chronic tension-type headache from the general population. Cephalalgia E-pub ahead of print

12. Aaseth K, Grande RB, Benth JS, Lundqvist C, Russell MB (2011) 3-Year followup of secondary chronic headaches: the Akershus study of chronic headache. Eur J Pain 15:186-192

13. Kristoffersen ES, Lundqvist C, Aaseth K, Grande RB, Russell MB (2013) Management of secondary chronic headache in the general population: the Akershus study of chronic headache. J Headache Pain 14:5

14. Johns MW (1991) A new method for measuring daytime sleepiness: the Epworth sleepiness scale. Sleep 14:540-545

15. Stewart WF, Lipton RB, Whyte J, Dowson A, Kolodner K, Liberman JN et al (1999) An international study to assess reliability of the Migraine Disability Assessment (MIDAS) score. Neurology 53:988-994

16. Headache Classification Committee of the International Headache Society (2013) The International Classification of Headache Disorders, 3rd edition (beta version). Cephalalgia 33:629-808

17. Sjaastad O, Fredriksen TA, Pfaffenrath V (1998) Cervicogenic headache: diagnostic criteria. The Cervicogenic Headache International Study Group. Headache 38:442-445

18. Benninger MS, Ferguson BJ, Hadley JA, Hamilos DL, Jacobs M, Kennedy DW et al (2003) Adult chronic rhinosinusitis: definitions, diagnosis, epidemiology, and pathophysiology. Otolaryngol Head Neck Surg 129:S1-32

19. Johns MW (1994) Sleepiness in different situations measured by the Epworth Sleepiness Scale. Sleep 17:703-710

20. Allison P (2012) Logistic Regression for Rare Events https:/statisticalhorizons. com/logistic-regression-for-rare-events (accessed June 2017)

21. Coveney J (2015) FIRTHLOGIT: Stata module to calculate bias reduction in logistic regression (Program)

22. Pallesen S, Nordhus IH, Omvik S, Sivertsen B, Tell GS, Bjorvatn B (2007) Prevalence and risk factors of subjective sleepiness in the general adult population. Sleep 30:619-624

23. Olesen J, Steiner T, Bousser MG, Diener HC, Dodick D, First MB et al (2009) Proposals for a new standardized general diagnostic criteria for the secondary headaches. Cephalalgia 29:1331-1336

24. Bogduk N, Govind J (2009) Cervicogenic headache: an assessment of the evidence on clinical diagnosis, invasive tests, and treatment. Lancet Neurol 8:959-968

25. Schrader H, Obelieniene D, Bovim G, Surkiene D, Mickeviciene D, Miseviciene I et al (1996) Natural evolution of late whiplash syndrome outside the medicolegal context. Lancet 347:1207-1211

26. Obermann M, Naegel S, Bosche B, Holle D (2015) An update on the management of posttraumatic headache. Ther Adv Neurol Disord 8:311-315

27. Fredriksen TA, Antonaci F, Sjaastad O (2015) Cervicogenic headache: too important to be left un-diagnosed. J Headache Pain 16:6

28. Rasmussen BK, Jensen R, Olesen J (1991) Questionnaire versus clinical interview in the diagnosis of headache. Headache 31:290-295

29. Jackson ML, Howard ME, Barnes M (2011) Cognition and daytime functioning in sleep-related breathing disorders. Prog Brain Res 190:53-68

30. Empana JP, Dauvilliers Y, Dartigues JF, Ritchie K, Gariepy J, Jouven $X$ et al (2009) Excessive daytime sleepiness is an independent risk indicator for cardiovascular mortality in community-dwelling elderly: the three city study. Stroke 40:1219-1224

\section{Submit your manuscript to a SpringerOpen ${ }^{\circ}$ journal and benefit from:}

- Convenient online submission

- Rigorous peer review

- Open access: articles freely available online

- High visibility within the field

- Retaining the copyright to your article 